\title{
Finite Element Modelation of Temperature and Residual Stress Caused by Welding
}

\author{
Labbe Fernando \\ Department of Mechanical Engineering, Federico Santa Maria Technical University, Chile
}

Copyright $(\mathcal{C} 2015$ by authors, all rights reserved. Authors agree that this article remains permanently open access under the terms of the Creative Commons Attribution License 4.0 International License.

\begin{abstract}
The temperature field and the residual stress were obtained using the finite element method (FEM), for a plane plate with a single-pass welding. The length and width of the plates were 250 and $300[\mathrm{~mm}]$ respectively, and three different thicknesses of $6.25,12.7$ and 25.4 [mm] $(1 / 4$ [in], $1 / 2$ [in] and 1 [in]) were considered. The model used was a two dimensional simplification of the three-dimensional actual problem, and the temperature field was calculated using an uncoupled scheme, this means, the temperature was calculated first and then the stress. The effects of different velocities of the arc between 6 and $8[\mathrm{~mm} / \mathrm{s}]$, initial temperature (preheat) between 20 and $200\left[{ }^{\circ} \mathrm{C}\right]$ (72 and 392 $\left.\left[{ }^{\circ} \mathrm{F}\right]\right)$, and thicknesses of the plate were studied regarding mainly about the final distribution and maximum values for the residual stress.
\end{abstract}

Keywords Residual Stress, Finite Element Method, Incompatibility, Welding

\section{Introduction}

During the manufacture of mechanical parts and pieces, the materials are subjected to processes that usually generate internal mechanical incompatibilities, giving as a result for example to the formation of plastic deformation, or inhomogeneous variations of the properties of the material. As a result of these incompatibilities, residual stress appears that remains even after the removal of the external loads. This is an important phenomenon especially for mechanical components that are welded. In this process, the body is under the effect of a thermal cycle with high temperature, local fusion, and a cooling. Due to this, high plastic deformations and variations on the properties of the material appear, and as a result it is expected large residual stresses. It has been proved that these stresses can be as high as the yield stress for the center of the weld line [1].

\subsection{Residual Stress: Foundations}

The residual stresses appear as a result of a permanent deformation or defects that alter the normal structure of a body. One of the most important characteristics of these stresses is that they are self-balanced [1], so

$$
\int \sigma d A=0 \text { and } \int d M=0
$$

Where $\sigma$ is the stress and $M$ the angular momentum.

\subsubsection{Incompatibility}

Consider the following decomposition of the deformation, which is valid for infinitesimal strain

$$
\varepsilon_{i j}=\varepsilon_{i j}^{e l}+\varepsilon_{i j}^{p l}
$$

In the equation (2), $\varepsilon_{i j}^{e l}$ is the elastic part of the deformation, and $\varepsilon_{i j}^{p l}$ is the plastic part. From the linear theory of elasticity, if the strain field is known, then in order to obtain a continuous displacement field, it is necessary the following condition called the compatibility equation [1] (see also [2] and [3])

$$
\begin{aligned}
& \left\{\frac{\partial^{2} \varepsilon_{x x}^{e l}}{\partial y^{2}}+\frac{\partial^{2} \varepsilon_{y y}^{e l}}{\partial x^{2}}-\frac{\partial^{2} \varepsilon_{x y}^{e l}}{\partial x \partial y}\right\} \\
& +\left\{\frac{\partial^{2} \varepsilon_{x x}^{p l}}{\partial y^{2}}+\frac{\partial^{2} \varepsilon_{y y}^{p l}}{\partial x^{2}}-\frac{\partial^{2} \varepsilon_{x y}^{p l}}{\partial x \partial y}\right\}=0
\end{aligned}
$$

Let $R$ defined as

$$
R=-\left\{\frac{\partial^{2} \varepsilon_{x x}^{p l}}{\partial y^{2}}+\frac{\partial^{2} \varepsilon_{y y}^{p l}}{\partial x^{2}}-\frac{\partial^{2} \varepsilon_{x y}^{p l}}{\partial x \partial y}\right\}
$$

$R$ is called the incompatibility. If $R \neq 0$, we have residual stress [1].

\subsection{Residual Stress as a Result of Thermal Loads}

Temperature is one of the principal sources of residual stresses. For welding its effects are not only related with the phenomena of dilatation and contraction, but also with the dependence of the thermal and mechanical properties of the 
material on the temperature. Additionally, the metallurgic phenomena such as the solid-solid and solid-liquid phase change are needed to be taken in consideration.

The sources of incompatibility are classified as follows for this kind of problem [1]:

- Mechanical incompatibility: incompatibility generated by the variation as a function of the temperature, of the mechanical properties such as the Young modulus $E$, Poisson ratio $v$, and yield stress $\sigma_{\mathrm{y}}$.

- Thermal incompatibility: incompatibility generated by the variation of the thermal properties as a function of the temperature, such as $\alpha, k, c_{p}$.

\section{Finite Element Model}

The figure (1) shows a scheme of the problem. On an ASTM A36 base metal, of length 250 [mm] (10 [in]), width of $300[\mathrm{~mm}](12$ [in]) and thickness $B$ (three different thicknesses were considered), it was deposited a welding groove using a GMAW process.

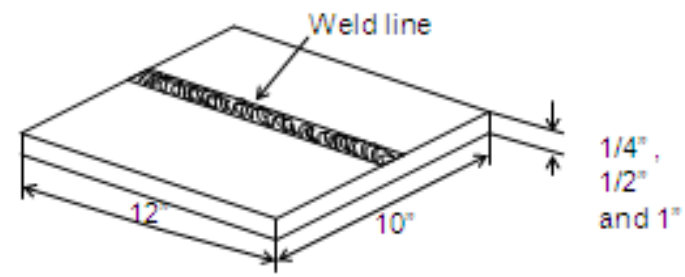

Figure 1. Scheme of the problem.

The thickness $B$ has the values $6.25,12.5$ and $25[\mathrm{~mm}](1 / 4$ [in], $1 / 2[$ in] and 1 [in] respectively)

The following were the welding parameters used for the three different thicknesses

- Arc voltage $V=30[\mathrm{~V}]$

- Current $I=250[\mathrm{~A}]$

- Arc velocity $\mathrm{v}=6$ and $12[\mathrm{~mm} / \mathrm{s}]$

- Arc efficiency $\eta=0.75$

Then the gross heat input can be calculated as [4]

$$
H=\frac{\eta V I}{v}
$$

The welding groove is located along a line in the middle of the plate (see figure 1).

The temperature and residual stress were calculated using the finite element code ABAQUS 5.6, the models have 450 and 2100 elements and nodes approximately. The generalized plane strain elements of 10 nodes were used.

Due to the symmetry of the temperature profile in $x$, with the exception of the border of the plate $[1,4]$ (see also $[5,6,7]$ for the same kind of approximation), and of the stress profiles in the $y$ direction, a two dimensional simplification of the problem was chosen. This was because to use a full three-dimensional model in general is too expensive; from the point of view of the time needed in order to process the numerical model (see for example [8], where a full three-dimensional model was developed in order to calculate the residual stresses for a pipe welding). So, it was assumed that the results that were obtained for example for the section $\mathrm{B}$ of the figure 2 were the same as the results obtained for the section A of the same figure, where A and B are far from the border of the plate.

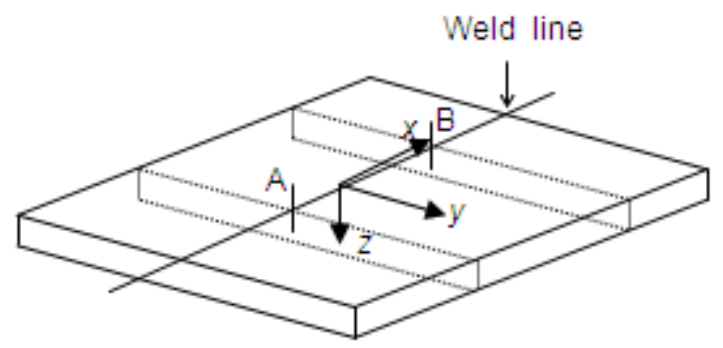

Figure 2. Coordinate frame and weld line.

The two-dimensional models, even so cheaper from the computational point of view, produce some problems about for example, how to model properly the welding arc, and about how to model the mechanical interaction of a section with the rest of the plate.

The effect of the welding was modeled by a heat flux per unit of length, which acts on a portion of the two-dimensional model, such that its magnitude varies as a function of time. Among some of the models that were considered [4,9], it was used the model proposed by Lee [4] (see also [10] for a discussion of the validity of the Gaussian distribution for the heat [9]).

The figure 3 shows the two-dimensional model with its boundary conditions, for the thermal and the stress problem. Due to the symmetry on $y$, it was modeled only half of the section $[4,5]$.

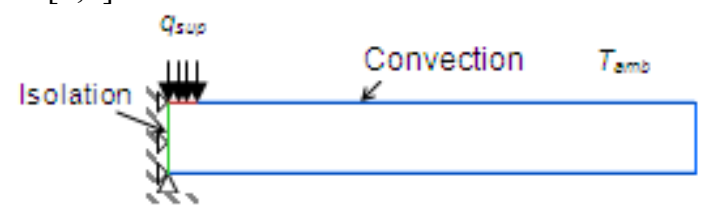

Figure 3. Boundary conditions for the thermal and stress problems.

The finite element mesh is shown in the figures 4 and 5 . The temperature versus time profile was stored for the point $\mathrm{A}, \mathrm{B}, \mathrm{C}, \mathrm{D}, \mathrm{E}, \mathrm{F}$ and $\mathrm{G}$ that are shown in the figure 6 . The important component of the residual stress is $\sigma_{\mathrm{xx}}[1]$, which is the normal component of the stress tensor $\sigma_{i j}$ in the direction $x$.

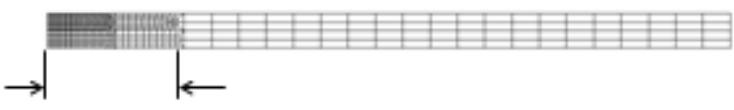

Figure 4. Mesh for the two-dimensional model.

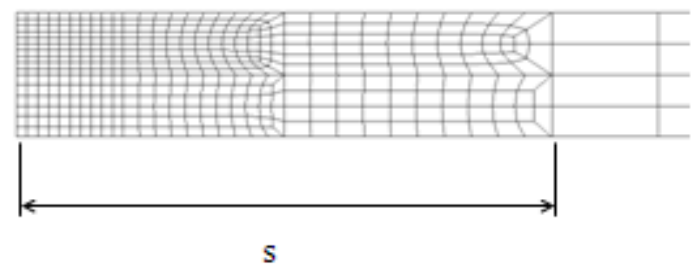

Figure 5. Mesh for the segment $\mathrm{s}$ of the figure 4 . 


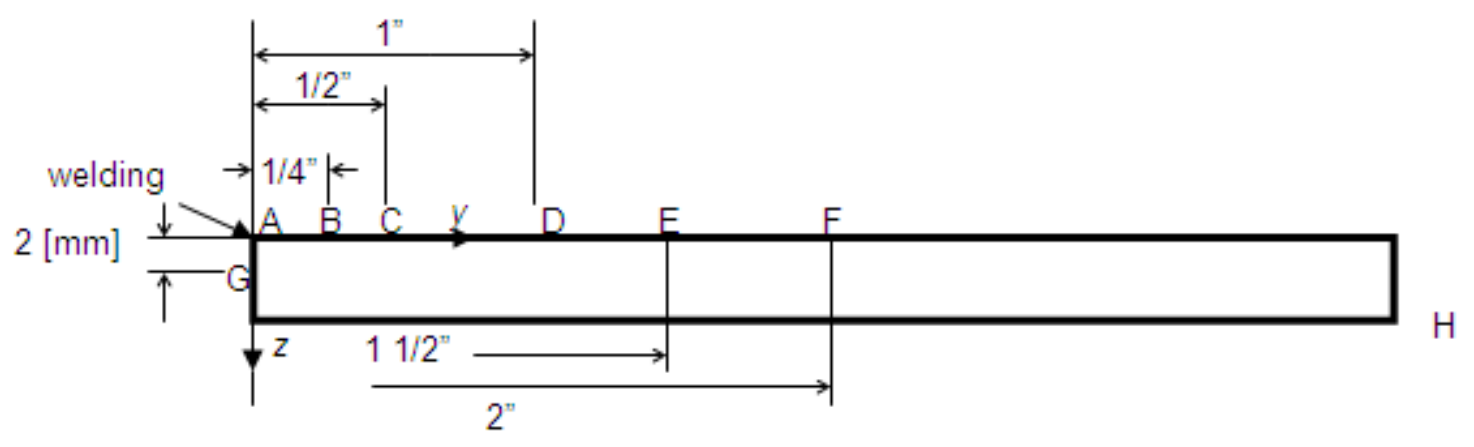

Figure 6. Points of measurement of the temperature.

\subsection{Residual Stresses as a Result of Thermal Loads}

As it was mentioned and proved by for example Masubushi [1] and Lee [4], the normal component in the direction $x$ of the stress is the most important in order to be computed. Then, it is essential to find an adequate model in order to consider the effect that exerts the rest of the body over the two-dimensional section. For example in the research done by Lee [4], the generalized plane strain elements were chosen in order to model this problem (see also [6,11]).

These elements have two extra nodes (besides the habitual 4 or 8 nodes of a plane finite element). A scheme of this element is shown in the figure 7.

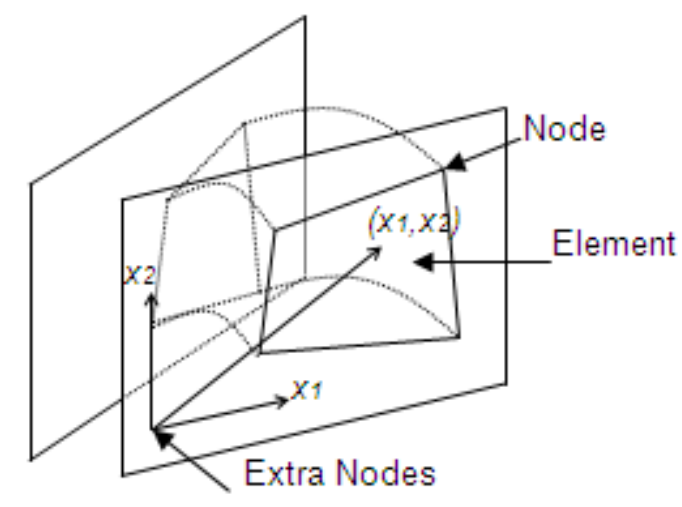

Figure 7. Generalized plane strain problem.

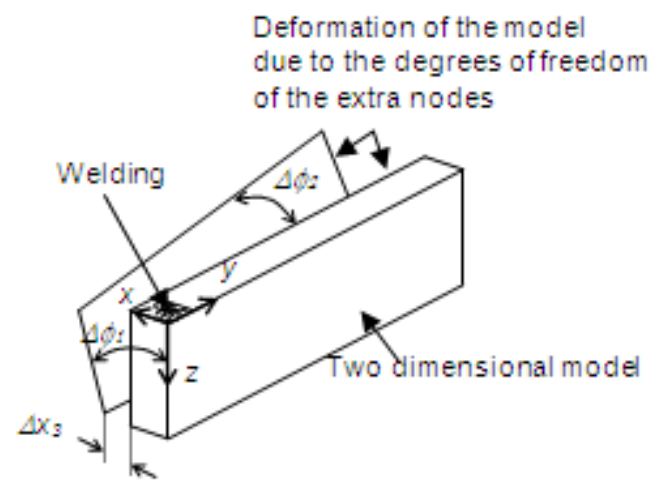

Figure 8. Deformation possible by using the generalized plane strain elements.

One of these nodes has a degree of freedom that allows the plane $y$-z to be deformed in $x$, meanwhile the other node has two degrees of freedom, which are related with an angular deformation around the $z$ and $y$ axis. So as a result, for our problem, one of the planes $y-z$ can develop a distortion as shown in the figure 8 .

From the three bar analogy for welding [1], the final effect for any section $y-z$ (far from the borders), corresponds to a compression zone in one extreme, and a traction zone in the other close to the weld line as it is shown in the figure 9 .

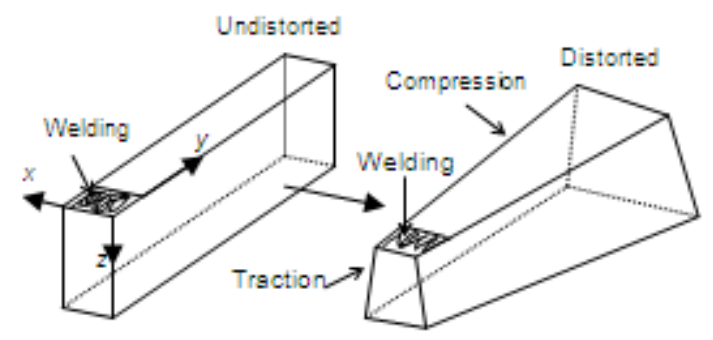

Figure 9. Deformation as a result of welding.

\subsection{Heat Flux}

The flux of heat, which simulates the pass of the welding arc over for example the section A, is modeled as a function of the time as it is indicated in the figure $10[4,7]$.

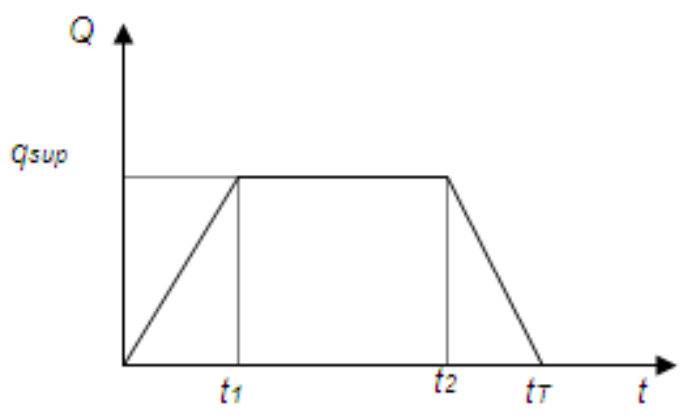

Figure 10. Heat flux as a function of time.

In the figure $10, q_{\text {sup }}$ is determined from [4]

$$
q_{\text {sup }}=\frac{\eta V I}{1055 b L}
$$

The time intervals $t_{1}, t_{2}, t_{T}$ are calculated as 


$$
\frac{t_{1}}{t_{1}+t_{2}}=p \quad t_{T}-t_{2}=t_{1}
$$

Finally the integral of the heat flux per unit of time, over the interval $\left[0, t_{T}\right]$ should be equal to the flux of heat due to the welding arc, so we have that

$$
b \int_{0}^{t_{T}} q d t=H
$$

Where $H$ is obtained as [4]

$$
H=\frac{\eta V I 60}{1055 v}
$$

These are the variables used

- $q_{\text {sup }}$ : Heat flux (maximum value) $\left[\mathrm{J} / \mathrm{mm}^{2} \mathrm{~s}\right]$

- $\quad \eta$ : Arc efficiency $=0.75$

- $V:$ : Voltage of the $\operatorname{arc}=30[\mathrm{~V}]$

- I : Electric current $=250[\mathrm{~A}]$

- $b:$ Welding width $=10[\mathrm{~mm}]$

- $\quad L:$ Thickness of the plane model $=25[\mathrm{~mm}]$

- $H$ : Flux of heat due to the welding arc.

- $v$ : Velocity of the arc.

\subsection{Material Properties}

Due to the significant variation in the temperature during the process, it is mandatory to consider the different properties of the material as functions of the temperature.

The base metal used was an ASTM 36, and the values of the Young coefficient $E$, the thermal conductivity $k$, the yield stress and thermal expansion coefficient $\alpha$, were taken from different references $[4,12,13]$. These properties were assumed constant and non-zero (for example for $k$ ) for temperatures higher than the fusion point (or the inferior critic temperature of the steel for $E$ and $\alpha$ ), this is due to the lack of reliable experimental data beyond these points. This is only an approximation of the real phenomena, but in the particular case of $E$ and $\alpha$, however, it is not possible in general by using a commercial FEM software, to model a body with a liquid portion on it, so in that case for temperatures higher than the inferior critical temperature, it was assumed that some of values of the properties such as $E$ were constant (but small in comparison with their normal values, see for example a somehow same kind of approximation used in [5]). Of course, there are many possibilities in order to approximate the material properties beyond the fusion or critical temperature, a detailed analysis of different models, and their impact on the final results can be found for example in the thesis of Bustamante [14].

\subsection{Organization of the Models}

In order to study at least one of the effect of the parameters, which are related directly with the welding process (affecting the heat flux from the arc), the temperature profiles, and residual stresses were obtained for different velocities of the arc.

About the dimension of the plate, the length and width were considered constant, and as it was mentioned previously, three different thicknesses were used. This was done in order to look for a relationship between the residual stresses, and the thickness of the plate $[4,15]$, considering the same velocity of the arc, and initial temperature.

About the initial temperature, one of the methods that have been used in order to reduce the level or magnitude of the residual stresses (even so it is not the most widely used), is the preheat [16]. Four different initial temperatures for the plate were considered (one of them is the temperature of the environment). The table 1 shows a summary of the different models.

Table 1. Summary of the models Thickness [inches]

\begin{tabular}{|c|c|c|c|c|c|}
\hline \multicolumn{7}{|c|}{ Thickness [inches] } \\
\hline $\begin{array}{c}\text { Speed } \\
{[\mathrm{mm} / \mathrm{s}]}\end{array}$ & $\begin{array}{c}\text { Initial } \\
\text { Temperature } \\
{\left[{ }^{\circ} \mathrm{F}\right]}\end{array}$ & $\begin{array}{c}\text { Speed } \\
{[\mathrm{mm} / \mathrm{s}]}\end{array}$ & $\begin{array}{c}\text { Initial } \\
\text { Temperature } \\
{\left[{ }^{\circ} \mathrm{F}\right]}\end{array}$ & $\begin{array}{c}\text { Speed } \\
{[\mathrm{mm} / \mathrm{s}]}\end{array}$ & $\begin{array}{c}\text { Initial } \\
\text { Temperature } \\
{\left[{ }^{\circ} \mathrm{F}\right]}\end{array}$ \\
\hline 6 & 72 & 6 & 72 & 6 & 72 \\
& 212 & & 212 & & 212 \\
& 302 & & 302 & & 302 \\
& 392 & & 392 & & 392 \\
\hline 8 & 72 & 8 & 72 & 8 & 72 \\
& 212 & & 212 & & 212 \\
& 302 & & 302 & & 302 \\
& 392 & & 392 & & 392 \\
\hline 10 & 72 & 10 & 72 & 10 & 72 \\
& 212 & & 212 & & 212 \\
& 302 & & 302 & & 302 \\
& 392 & & 392 & & 392 \\
\hline 12 & 72 & 12 & 72 & 12 & 72 \\
& 212 & & 212 & & 212 \\
& 302 & & 302 & & 302 \\
& 392 & & 392 & & 392 \\
\hline
\end{tabular}




\subsection{Numeric Results}

The numeric results were obtained by using an uncoupled scheme $[17,18]$. We show the results separately for the temperature and residual stresses.

\subsubsection{Results for the Temperature}

The figures 11 to 14 show the profile of temperature versus time for the section $\mathrm{A}$, and for different positions along the $y$ axis (over the superior surface of the plates, see figure 6), thicknesses, velocities of the arc, and an initial temperature of $70\left[{ }^{\circ} \mathrm{F}\right]$.

The figure 15 shows the comparison between the numeric and experimental results for the plate of $1 / 2$ [in], and for a position of 1 [in] from the weld line (point D of the figure 6). These experimental results were obtained by using a thermocouple. As it can be seen, both results, experimental and numerical agree considerably.

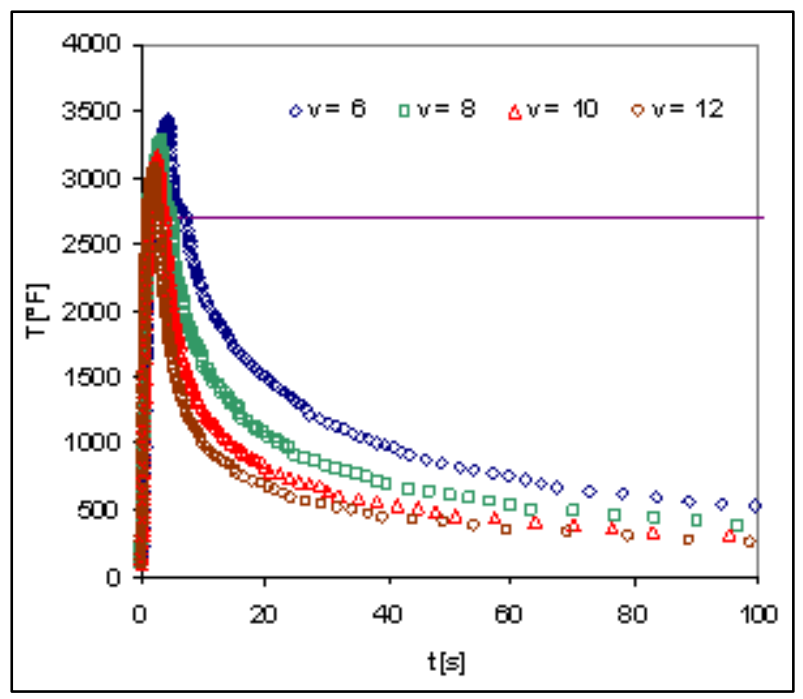

Figure 11. Effect of the arc velocity on the temperature profile for the $1 / 4$ (in) plate and initial temperature $\mathrm{T} 0$ of $70\left({ }^{\circ} \mathrm{F}\right)$, at $\mathrm{y}=0$.

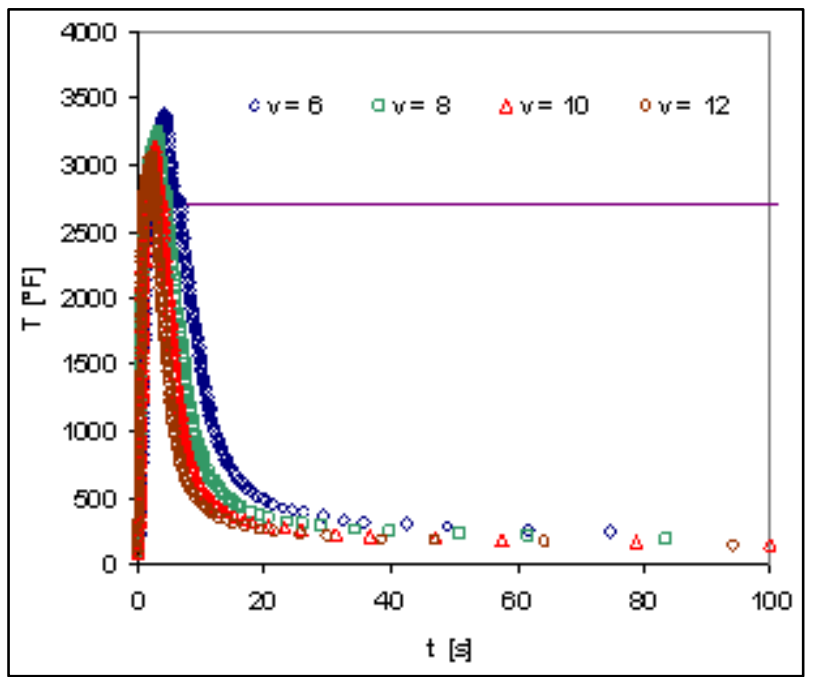

Figure 12. Effect of the arc velocity on the temperature profile, for the 1(in) plate and initial temperature of $70\left({ }^{\circ} \mathrm{F}\right)$, at $\mathrm{y}=0$.

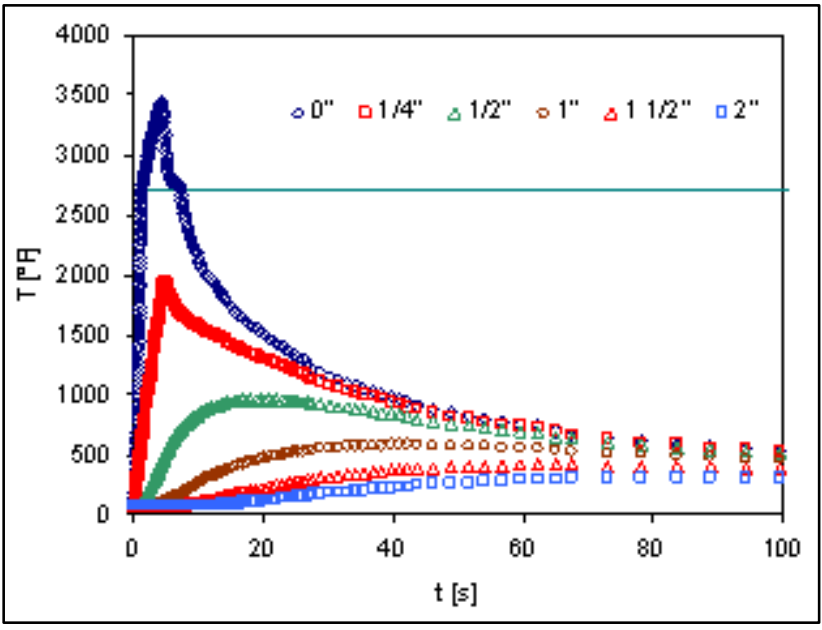

Figure 13. Temperature versus time for different point along the $1 / 4$ (in) plate, with $70\left({ }^{\circ} \mathrm{F}\right)$, and a velocity of $6(\mathrm{~mm} / \mathrm{s})$.

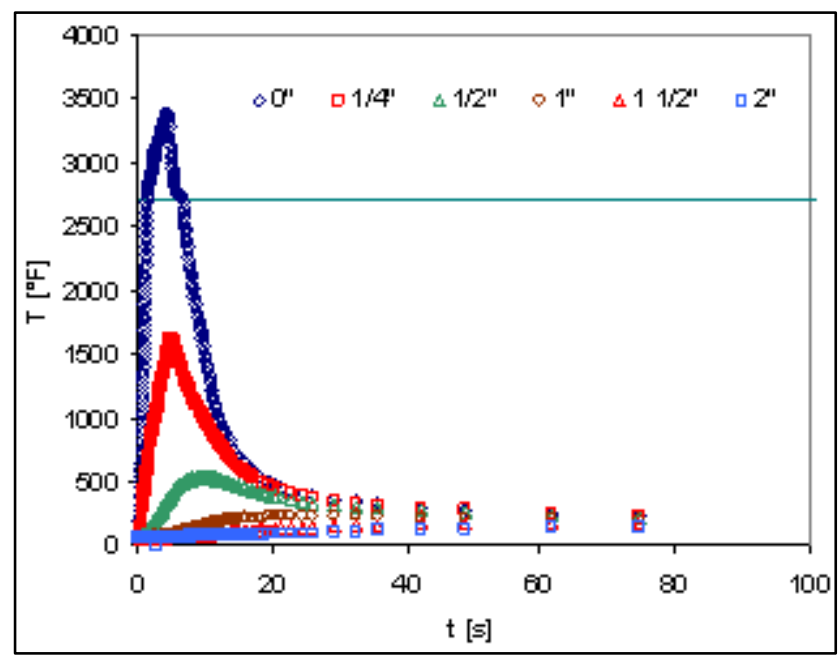

Figure 14. Temperature versus time for different point along $1 / 4($ in), with $\mathrm{T} 0=70^{\circ} \mathrm{F}$, and a velocity of $6(\mathrm{~mm} / \mathrm{s})$.

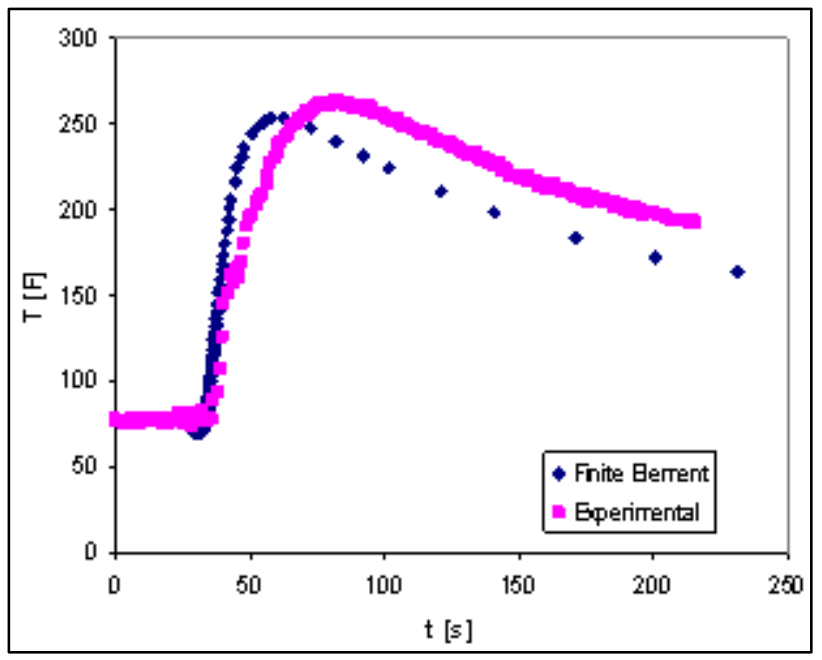

Figure 15. Experimental and numerical results as a function of time for the $1 / 4$ (in) plate. 
These results can also be checked by using the following approximate expression, in order to obtain the maximum temperature as function of the distance $y$ [19].

$$
\frac{1}{T_{p}-T_{0}}=\sqrt{2 \pi b_{\ln }} \frac{\rho c e y}{H}-\frac{1}{T_{m}-T_{0}}
$$

Where

- $T_{p} \quad$ : Maximum temperature

- $b_{l n} \quad$ : Basis for the natural logarithm $=2.718$

- $B \quad$ : Plate thickness

The results obtained with the above formula are contrasted with our numerical results for $y=1 / 2$ [in]. These results are shown in the table 2.

\subsubsection{Results for the Residual Stress.}

The results for the residual stresses are presented in the figures 16 to 20 , and they correspond to the normal component of the stress (in the direction $x$ of the figure 2), along $y$.

As it can be seen from the figures 16 and 17, a preheat gives as a result a decreasing on the maximum value of the residual stress [16]. The reason is because a higher initial temperature, reduces the impact that has the suddenly increase in the temperature, due to the movement of the arc. The figure 16 and 27, show that the effect is more important (as a percentage) for the $1 / 4$ than the 1 [in] thickness plate, for a velocity of $6[\mathrm{~mm} / \mathrm{s}]$.
The velocity of the arc is one of the parameters of welding, which can be modified easily in an automated process. The velocity has a direct impact in the heat flux. A higher velocity means less time of permanence of the arc on any section along $x$ (figure 2). So we would have a decrease in the residual stresses.

The figures 18 and 19 show the results obtained for the plate of $1 / 4$ and 1 [in], for different velocities from 6 to 12 $[\mathrm{mm} / \mathrm{s}]$, which confirm our previous statement.

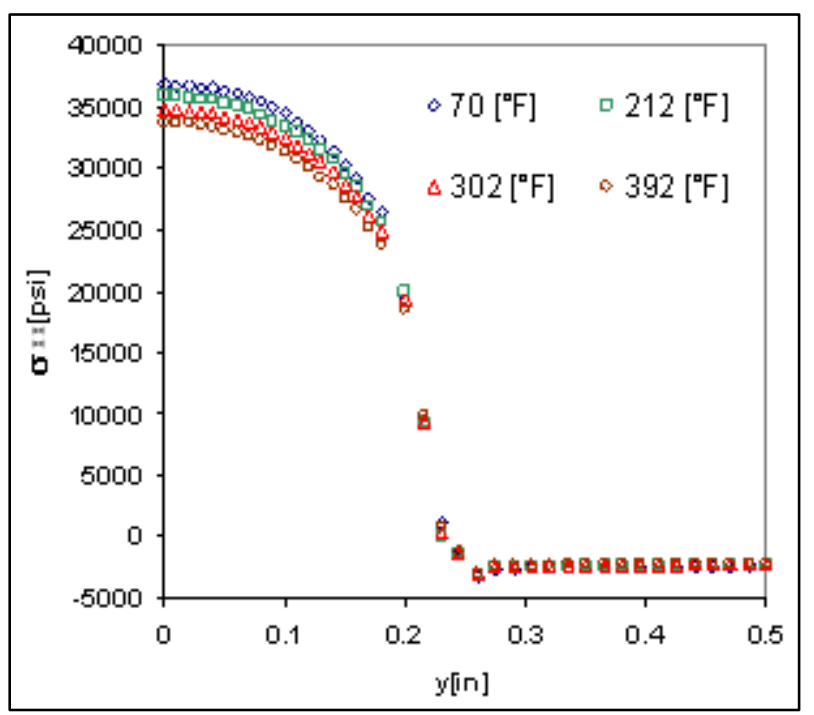

Figure 16. Residual stress for the $1 / 4$ (in) plate, for an arc velocity of 6 $(\mathrm{mm} / \mathrm{s})$ and for different initial temperature.

Table 2. Comparison of $T_{p}$ calculated by using eq. (10) with the numeric results, for $y=1 / 2$ [in].

\begin{tabular}{|l|c|c|c|c|}
\hline \multirow{2}{*}{$1 / 4$ [inches] Plate } & \multicolumn{5}{|c|}{} \\
\cline { 2 - 5 } Initial temperature [ ${ }^{\circ}$ F] & \multicolumn{3}{|c|}{70} & \multicolumn{2}{|c|}{392} \\
\cline { 2 - 5 } Speed [mm/s] & 6 & 12 & 6 & 12 \\
\cline { 2 - 5 } Finite Element & 960 & 609 & 1166 & 857 \\
Formula & 1098 & 705 & 1370 & 1007 \\
error \% & 12.6 & 13.6 & 14.9 & 14.9 \\
\hline
\end{tabular}

\begin{tabular}{|l|c|c|c|c|}
\hline \multirow{2}{*}{$1 / 2$ [inches] Plate } & \multicolumn{5}{|c|}{} \\
\cline { 2 - 5 } Initial temperature [ ${ }^{\circ}$ F] & \multicolumn{2}{|c|}{70} & \multicolumn{2}{|c|}{392} \\
\cline { 2 - 5 } Speed [mm/s] & 6 & 12 & 6 & 12 \\
\cline { 2 - 5 } Finite Element & 622 & 380 & 873 & 662 \\
Formula & 705 & 430 & 1007 & 745 \\
error \% & 11.8 & 11.6 & 13.3 & 11.1 \\
\hline
\end{tabular}

\begin{tabular}{|l|c|c|c|c|}
\hline \multirow{2}{*}{1 [inches] Plate } & \multicolumn{5}{|c|}{} \\
\cline { 2 - 5 } Initial temperature [ $\left.{ }^{\circ} \mathrm{F}\right]$ & \multicolumn{2}{|c|}{70} & \multicolumn{2}{|c|}{392} \\
\cline { 2 - 5 } Speed [mm/s] & 6 & 12 & 6 & 12 \\
\cline { 2 - 5 } Finite Element & 535 & 348 & 805 & 634 \\
Formula & 430 & 263 & 745 & 583 \\
error \% & 24.4 & 32.3 & 8.1 & 8.7 \\
\hline
\end{tabular}




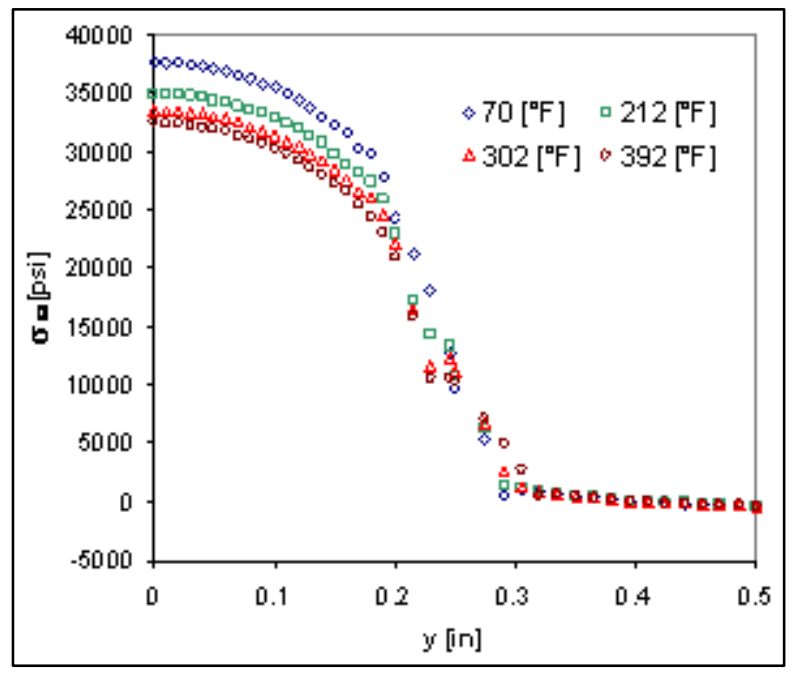

Figure 17. Residual stress for the $1 / 4$ (in) plate, for different arc velocities and different temperatures.

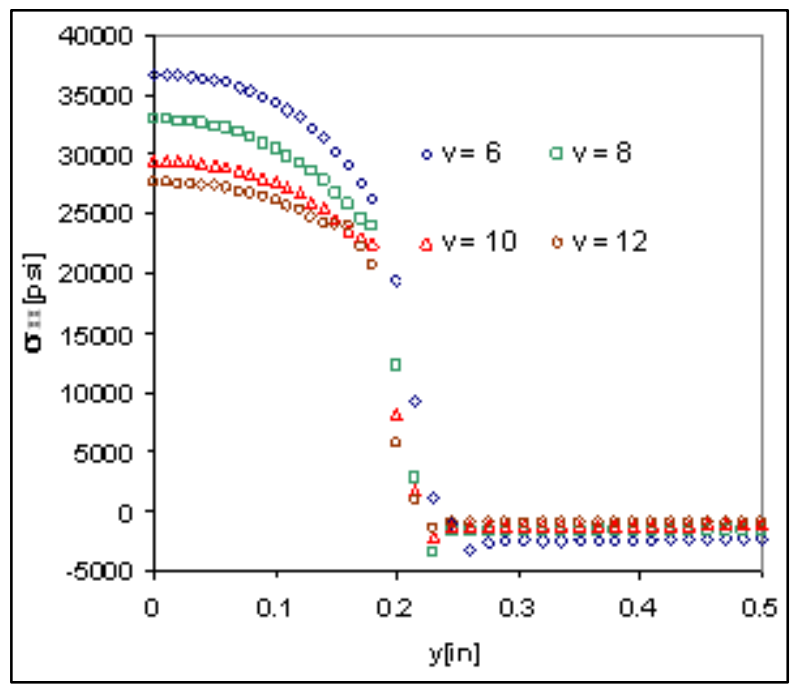

Figure 18. Residual stress for the plate of $1 / 4$ (in), for an initial temperature of $70\left({ }^{\circ} \mathrm{F}\right)$

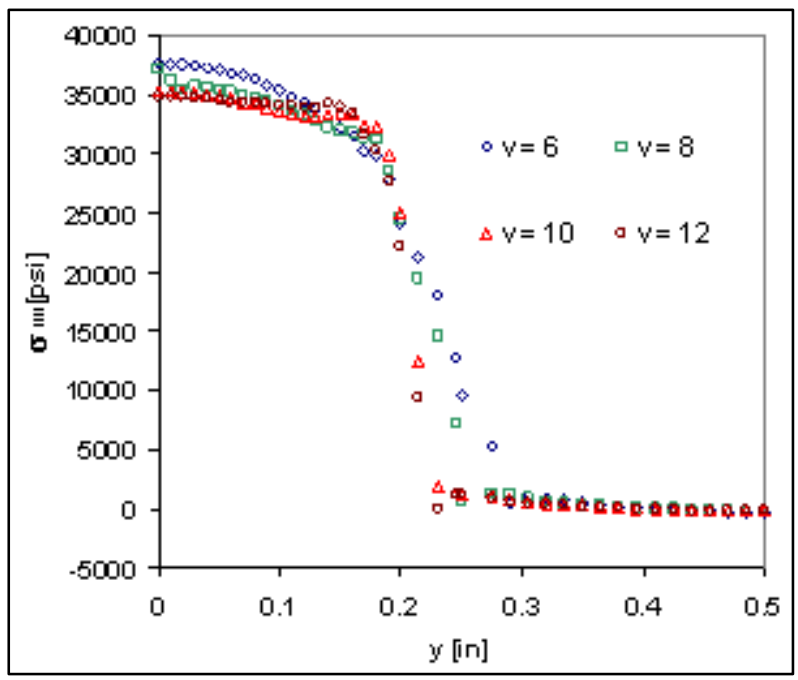

Figure 19. Residual stress for the plate of 1 (in), for initial temperature of $70\left({ }^{\circ} \mathrm{F}\right)$

\section{Conclusions}

Due to the uncoupled scheme used in order to solve the thermo elastic problem, we discuss our results separately for the temperature and stress problems.

\subsection{Modeling of the Temperature}

The highest temperature, which can be reached in a welding process, can surpass widely the fusion point, as it can be seen from the figures 11 and 12. The effect that the initial temperature of the plate may have on the maximum level of temperature is not relevant, however, regarding the effect of the velocity of the arc, as it can be seen from the figures 11 and 12, lower maximum temperatures are obtained for higher arc velocities.

The figure 15 shows two profiles of temperature versus time, one of them was obtained by using the finite element method and the other experimentally by using a thermocouple. The maximum difference (relative) was of $3 \%$ that indicates a good agreement between our model and the experimental results. There is however a small difference in the phase, the reason is because the experiment was done over the real three-dimensional plate, and then this difference is the result of the interval of time that our two-dimensional model has to wait, in order to perceive the arc. As a result both profiles had to be moved relatively (but not perfectly) in order to be compared.

\subsection{Modeling of the Residual Stresses}

We do not have experimental or other numerical data, for exactly the same dimensions of the plates in order to compare them with our results for the stress. For some of the cited references, the shape of the structures or bodies considered were different, see for example $[4,7,12,15]$. About the research done by Lee [4], the residual stresses were calculated for plane plates but with smaller width.

One of the important characteristics of the residual stresses, is that they are self balanced, which means

$$
\int \sigma_{x x} d y=0
$$

So, the summation of the forces should be equal to zero [1]. In the table 3, the results for the integral (11) can be seen for the different models.

The values of the integral for our models are not zero, and then in principle our models would not satisfy this basic condition.

A better way in order to verify if our model is or not a good approximation in relation with the condition (11), is by using the average stress, that we define as [14]

$$
\sigma_{m}=\frac{\int \sigma_{x x} d y}{L}
$$

In the above equation $L$ corresponds to half of the plate width. 
This average stress may be considered as the permanent effect, which remains in the plate at the final of the process. If we take as a reference value the maximum stress for the center of the weld line, $\sigma_{\max }$, which is approximately 36000 [psi], we can calculate the quotient $\sigma_{\mathrm{m}} / \sigma_{\max }$ that from the table 3 , has a mean value between 0.9 and $3.55 \%$. So the real final effect is comparatively small, and we could conclude that our model satisfy (approximately) the condition (11).

Table 3. Integral of the stress and average stress for the different models.

\begin{tabular}{|c|c|c|c|}
\hline \multicolumn{4}{|c|}{ 1/4 [in] Plate } \\
\hline \multicolumn{4}{|c|}{$v=6[\mathrm{~mm} / \mathrm{s}]$} \\
\hline To & Integral [psi in] & $\sigma m$ & $\sigma m / \sigma \max \%$ \\
\hline 70 & 1640 & 328 & 0.94 \\
\hline 392 & 1573 & 314.6 & 0.90 \\
\hline \multicolumn{4}{|c|}{$v=12[\mathrm{~mm} / \mathrm{s}]$} \\
\hline To & Integral [psi in] & $\sigma m$ & $\sigma m / \sigma \max \%$ \\
\hline 70 & 2518 & 503.6 & 1.44 \\
\hline 392 & 2137 & 427.4 & 1.22 \\
\hline \multicolumn{4}{|c|}{$1 / 2$ [in] Plate } \\
\hline \multicolumn{4}{|c|}{$v=6[\mathrm{~mm} / \mathrm{s}]$} \\
\hline To & Integral [psi in] & $\sigma_{m}$ & $\sigma m / \sigma \max \%$ \\
\hline 70 & 3901 & 780.2 & 2.23 \\
\hline 392 & 3247 & 649.4 & 1.86 \\
\hline \multicolumn{4}{|c|}{$v=12[\mathrm{~mm} / \mathrm{s}]$} \\
\hline To & Integral [psi in] & $\sigma m$ & $\sigma m / \sigma \max \%$ \\
\hline 70 & 4556 & 911.2 & 2.60 \\
\hline 392 & 3757 & 751.4 & 2.15 \\
\hline \multicolumn{4}{|c|}{1 [in] Plate } \\
\hline \multicolumn{4}{|c|}{$v=6[\mathrm{~mm} / \mathrm{s}]$} \\
\hline To & Integral [psi in] & $\sigma m$ & $\sigma m / \sigma \max \%$ \\
\hline 70 & 6221 & 1244.2 & 3.55 \\
\hline 392 & 5327 & 1065.4 & 3.04 \\
\hline \multicolumn{4}{|c|}{$v=12[\mathrm{~mm} / \mathrm{s}]$} \\
\hline To & Integral [psi in] & $\sigma m$ & $\sigma m / \sigma \max \%$ \\
\hline 70 & 6208 & 1241.6 & 3.55 \\
\hline 392 & 5253 & 1050.6 & 3.00 \\
\hline
\end{tabular}

From the figures 16 and 17, it can be inferred that a higher initial temperature (preheat), provokes a decrease on the residual stresses. As an example, for the $1 / 4$ [in] plate (figure 16), there is a difference of 2500 [psi] (for the maximum stress), between the model with an initial temperature of 70 $\left[{ }^{\circ} \mathrm{F}\right]$ and the model with $392\left[{ }^{\circ} \mathrm{F}\right]$.

About the velocity of the arc, as it was mentioned, a higher velocity implies a lower maximum temperature, and from the figures 18 and 19, it can be appreciated a lower level for the residual stresses, being the difference of the magnitude of the stress for the highest and lowest velocity of 8000 [psi] approximately.

\section{REFERENCES}

[1] Masubuchi, K. 1980. Analysis of Welded Structures: Residual Stresses, Distortion, and Their Consequences (International series on materials science and technology; v. 33), Pergamon Press.

[2] Fung, Y. C. 1965. Foundations of Solids Mechanics, New Jersey, Prentice Hall, Inc., Englewood Cliffs.

[3] Green, A. E., Zerna, W. 2002. Theoretical Elasticity, Dover Publications.

[4] Lee, S. G. 1992. Modeling of residual stress in thick section weldments. PhD dissertation, The Ohio State University.

[5] Friedmann, E. 1975. Thermomechanical analysis of the welding process using the finite element method. Journal of Pressure Vessel Technology, 97, Series J \#3: 206-s to 160-s.

[6] Josefon, B. L. 1985. Effects of transformation plasticity on welding residual-stress fields in thin-walled pipes and thin plates. Material Science and Technology, October 1985, 1: 904-s to 908 -s.

[7] Wikandes, L., Karlsson, L., Näsströn, M., Webster P. 1994. Finite element simulation and measurement of welding residual stresses. Modelling Simul. Mater. Sci. Eng. 2: 845-s to 864 -s.

[8] Fricke, L., Kein, E., Schmidt, J. 2001. Numerical weld modeling- a method for calculating weld-induced residual stresses. Nuclear Engineering and Design 206:139-s to150-s.

[9] Pando, E. 1987. Aplicación de métodos numéricos al problema de flujo térmico en uniones soldadas. Trabajo de tesis para optar al grado académico de doctor en ciencias de materiales, Universidad Nacional del Mar del Plata, Argentina.

[10] Jeng, Ming-Chang., Wu, Cheng-Tang,. 1994. Finite element modeling of heat transfer and residual stress analysis for electron beam welding. Chung-Kuo Chi Hsueh Kung Ch'eng Hsueh Pao/ Journal of the Chinese society of mechanical engineers, 15 (1): 1 -s to 10 -s.

[11] Hibbit, Karlson and Sorensen, 2013. ABAQUS User's manual. Inc., Providence, R. I..

[12] Hong, J. K., Tsai, C. L., Dong, P. 1998. Assessment of numerical procedures for residual stress analysis of multi-pass welds. Welding Journal Sep.: 372-s to 382-s.

[13] Mundra, K., Debroy, T., Babu, S. S., David, A. 1997. Weld metal microstructure calculation from fundamentals of transport phenomena in the arc welding of low-alloy steels, Welding Journal, Apr.: 163-s to 171-s.

[14] Bustamante, R. 2000. Modelación por medio del método de elementos finitos de los campos de temperatura y esfuerzos residuales en uniones soldadas. Memoria de ingeniero civil mecánico, Universidad Técnica Federico Santa Maria, Valparaíso, Chile.

[15] Micharelis, P., Dantzing, J., Tortorelli, D. 1999. Minimization of welding residual stress and distortion in large structures. Welding Journal Nov.: 361-s to 366-s. 
[16] Adedayo, S. M., Adeyemi, M. B. 2000. Effect of preheat on residual stress distribution in arc-welded mild steel plates. Journal of Material Engineering and Performance 9 (1): 7-s to 11 -s.

[17] Bathe, K. J. 1982. Finite Element Procedure in Engineering Analysis. Prentice-Hall Civil Engineering and Engineering
Mechanics Series.

[18] Boley, B., Weimer, J. 1997. Theory of Thermal Stresses. , New York, Mineola Dover Publications, Inc.

[19] American Welding Society. 1991. Welding Handbook. Vol. 1, Welding Technology, Eight Edition. 